\title{
The Distribution and Temporal Change of Mercury in a Sewage Treatment Plant
}

\author{
1.Cui Ying1,Institute of Resources \&Environment \\ Henan Polytechnic University, \\ Jiaozuo,454003,China \\ e-mail:abinever@163.com
}

\begin{abstract}
In order to understand the distribution characteristics and temporal change of mercury species in a sewage treatment plant,sewage and sludge samples were collected from influent and effluent of the Second Sewage Treatment Plant of Jiaozuo for 10 months.Atomic Fluorescence method was used to detect mercury.Total mercury (THg) and methylmercury ( $\mathrm{MeHg}$ ) were found the average concentrations of $2.00 \times 103 n g / L$ and 16.2ng/L.THg in grit chamber mainly exists with granule state.THg were positively correlated to TSS $(\mathbf{P}=\mathbf{0 . 0 0 3})$. $\mathrm{MeHg}$ and dissolved $\mathrm{MeHg}$ of influent were found at average concentrations of $7.5 \mathrm{ng} / \mathrm{L}$ and $0.59 \mathrm{ng} / \mathrm{L}$.Inffluent THg and MeHg concentrations have correlation with TSS concentrations $(P=0.003, P=0.035)$.Dissolved $\mathrm{MeHg}$ was increases with the temperature rising. THg and Dissolved THg of effluent were found at the average concentrations of 10.6ng/L and 2.2ng/L. Mean daily removals of $\mathrm{THg}$ and dissolved THg at the plant were $98.9 \%$ and $65 \%$. The ratio (Dissolved THg/THg) has increased in effluent.MeHg and dissolved $\mathrm{MeHg}$ of effluent were found that the average concentrations of $0.33 \mathrm{ng} / \mathrm{L}$ and $0.1 \mathrm{ng} / \mathrm{L}$. THg and $\mathrm{MeHg}$ contents of the effluent met the requirement of "Urban sewage treatment plant pollutant discharge standard" (GB18918-2002). Mean daily removals of $\mathrm{MeHg}$ and dissolved MeHg were $93.5 \%$ and $70.7 \%$. MeHg removal efficiency is higher than dissolved MeHg removal efficiency and the MeHg removal efficiency is lower than the $\mathrm{THg}$ removal efficiency.The pressure-filter sludge ( $(3.94 \pm 0.53)$ $\times 103 \mathrm{ng} / \mathrm{g}$ ) was greater than the national standard for soil environmental quality of grade iii.The average concentrations of $\mathrm{MeHg}$ was $6.35 \pm 0.84 \mathrm{ng} / \mathrm{g}$. The ratio of MeHg accounted for $\mathrm{THg}$ was minimal(less than $1 \%$ ). Using the Index of geoaccumulation and potential ecological risk index method to analysis $\mathrm{THg}$ in pressure-filter sludge.The result of indicated that $\mathrm{THg}$ in pressure-filter sludge have high potential ecological risk. Thus the sludge might not be applied to farm land after suitable treatments.
\end{abstract}

Keywords-THg;Dissolved THg;MeHg;Dissolved MeHg; Pressure-filter sludge

\author{
2.Ma Bingjuan2, Institute of Resources \\ \&Evironment \\ Henan Polytechnic University \\ Jiaozuo, 454003, China \\ e-mail:mbj@hpu.edu.cn
}

I. INTRODUCTION

Mercury is one of the highly toxic heavy metal elements that cause environmental pollution.In the world,more than 10000 tons of mercury is mined every year,and about 5000 tons were lost[1],which has leaded the content of mercury in the ambient medium to nearly three times more than the industrial revolution, and caused serious Environment pollution.The inorganic mercury in the environment,through the action of biological and non-biological methylation,can thansform into more poisonous methyl mercury.It would cause harm to human health through the food chain enter human body[2].

With the speeding up of urbanization process and the ability of sewage treatment improving, urban sewage treatment plants become the main collection of people production and living pollutants.By the end of 2013 ,sewage treatment capacity is about $1.47 \times 108$ $\mathrm{m} 3 /$ day, processing power is about $6.8 \times 106 \mathrm{~m} 3 /$ day more than the end of 2012[3].According to statistics, the process of urban sewage treatment would produce city sludge, whose volume was $0.02 \%$ of the whole volume of sewage[4]. In our country, by the end of September 2011 , the annual production of wet discharge sludge (moisture content $80 \%$ ) has reached 34.8 million tons [5].

Domestic and International studies have found that inorganic and methyl mercury may generally exists in the urban sewage,the processing of sewage treatment plant effluent and sludge in the city.At present a domestic study of mercury content in municipal sewage of Beijing found that the total mercury levels between $0.21 \sim$ $2.23 \mu \mathrm{g} / \mathrm{L}[6]$.The research of sludge dewatering of Jianxi district sewage treatment plant by Ge Xiaoyan[7].They found that the mean concent of sludge samples of mercury $(6.57 \mathrm{ug} / \mathrm{g})$ is higher than the national average (3.18 ug/g). MeHg is very limited to study each operating unit of urban sewage treatment plants and sludge in China.The research of Gilmour and Bloom for a sewage treatment plant in Pennsylvania shown that the contents of $\mathrm{THg}$ in the wastewater was $156 \mathrm{~g} / \mathrm{day}$, after processing, about $95 \%$ of the $\mathrm{THg}$ exists in sludge, only $6 \sim 7 \mathrm{~g}$ /day $\mathrm{THg}$ into the receiving waters. At the same time, the secondary treatment effluent and sludge were 
detected in $\mathrm{MeHg}$, the concentration of them were 1.01 $3.15 \mathrm{ng} / \mathrm{L}, 4.03 \sim 5.69 \mathrm{ng} / \mathrm{L}, 1.6 \sim 5.2 \mathrm{ng} / \mathrm{g}[8]$. The analyzation of three life sewage treatment plant of Canada from Bodaly, the concentration of $\mathrm{THg}$ in sewage for $2 \sim 160 \mathrm{ng} / \mathrm{L}, \mathrm{MeHg}$ concentration was $0.5 \sim$ 4.3ng/L,the $\mathrm{THg}$ concentration of procesed sewage reduced to $3 \sim 14 \mathrm{ng} / \mathrm{L}, \mathrm{MeHg}$ concentration reduced to $0.1 \sim 0.4 \mathrm{ng} / \mathrm{L}$. The temperature has an effect on concentration of $\mathrm{MeHg}$ [9].In view of this,Sewage and sludge of the second sewage treatment plant of Jiaozuo were researched,studied the distribution characteristics and temporal change of mercury species in a sewage treatment plant. The results of the study for the prevention of urban sewage in the inorganic mercury and $\mathrm{MeHg}$ pollution,assessment of sewage and sludge discharge and disposal of the environmental and for health risks provide scientific basis.

\section{A. Sample collection and pretreatment}

The second sewage treatment plant of Jiaozuo where is located in the eastern of Jiaozuo Harvest Road,it has a surface area of $8.09 \times 104 \mathrm{~m} 2$.it provides high quality treatment of wastewater for 300,000 people and received most of domestic wastewater from the east of Shanyang district, Macun district, JiaoNan new district and the south of Shahe district.In addition to open channel(Wengjian River and Li River.) input.One part of processed sewage was reused in the plant,the rest of the processed sewage released into the New River. The second sewage treatment plant of Jiaozuo has used improved oxidation ditch process. The whole process system is composed of four parts:pretreatment system,biochemical treatment system.sludge treatment system and disinfection system(Fig .1-1.).

\section{MATERIAL AND METHODS}

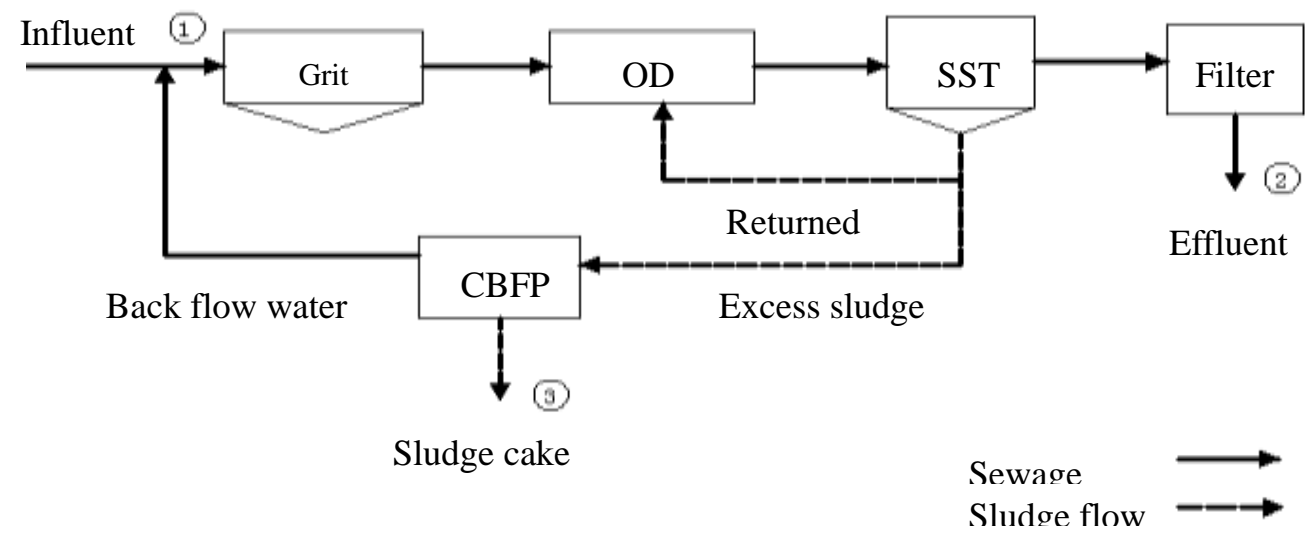

Figure1-1.Schematic Diagram of the Second Sewage Treatment Palant of Jiaozuo

Whole water grab samples were collected in raw sewage at the influent (1), the effluent (2) and the press filter sludge (3) for $\mathrm{THg}$ and $\mathrm{MeHg}$ analysis in the Sewage treatment plant for ten months(November,2014 October,2015, Do not include January and February,2015).Samples were collected each month 10 between 8:00 AM to 18:00 PM and collected every two hours.All samples were collected in acid-washed Teflon bottles,double bagged and put in clean cooler ice,transported them to the laboratory. $\mathrm{THg}$ and $\mathrm{MeHg}$ samples that were preserved by the addition of concentrated trace-metal grade $\mathrm{HCl}(5 \%)$ acid stored refrigerated, while those for $\mathrm{MeHg}$ analysis were frozen.Filtered and unfiltered samples were split for determination of $\mathrm{THg}$ and $\mathrm{MeHg}$. Approximately $500 \mathrm{~mL}$ of each sample was filtered under vacuum using an acid-cleaned disposable filter unit $(0.45 \mu \mathrm{m}$, cellulose membrane).Sludge samples were freezed and dried,grinded and sieved through 100 mesh sieve, and then sealed cryopreservation.

\section{B. The analysis method of the sample}

\section{1) The analysis method of $\mathrm{THg}$}

Samples were oxidized used $\mathrm{BrCl}$ to release $\mathrm{Hg}$ from particles and organic complexes,then pre-reduced using hydroxylamine hydrochloride,prior to quantification by tin chloride( $\mathrm{SnCl}$ ) reduction. Sewage Samples were analyzed using standard techniques for $\mathrm{Hg}$ analysis by cold vapor atomic fluorescence spectrometry (CVAFS).This method is outlined in USEPA Method 1631.Detection limit was $0.5 \mathrm{ng} / \mathrm{L}[10]$.

Sewage sludge samples were analyzed for $\mathrm{MeHg}$ by DMA80 mercury analyzer.Before determined the standard and sample,using $100 \mathrm{~mL}, 0.5 \sim 1 \mathrm{~mol} / \mathrm{L} \mathrm{HNO} 3$ to repeat analysis,until absorbance fluctuation was less than 0.0030 and ran the blank quartz plate.

\section{2) The analysis method of $\mathrm{MeHg}$}

Sewage Samples were digested with $\mathrm{KBr} / \mathrm{H} 2 \mathrm{SO} 4$ solution $(2 \mathrm{~mL})$ and $\mathrm{CuSO} 4$ solution $(1 \mathrm{~mL})$,extracted with $\mathrm{CH} 2 \mathrm{Cl} 2$ and reverse extracted in water with water bath $\left(45^{\circ} \mathrm{C}\right)[11]$.After reverse extracted,samples were ethylated with sodium tetraethylborate solution,followed by purging of volatile methylethyl $\mathrm{Hg}$ onto Tenax carbotrap,and then separation by isothermal gas chromatography and CVAFS detecting MeHg.Detection limit was $0.06 \mathrm{ng} / \mathrm{L}$. 
Sludge MeHg sample detection method is the same with the method of detection for Sewage Samples.Detection limit was $0.12 \mathrm{ng} / \mathrm{g}$.

Frequent calibration standard checks and procedural blank analyses helped assure analytical accuracy.Analytical results were as follows: ERM-CC580,certified value $=132 \pm 3 \mathrm{mg} / \mathrm{kg}(\mathrm{THg})$, certified

value $=75.5 \pm 4 \mathrm{ug} / \mathrm{kg}(\mathrm{MeHg})$. Analytical accuracy was checked by multiple daily analyses of each of three different certified reference, mean RSD were $10 \%(\mathrm{THg})$ and $15 \%(\mathrm{MeHg})$. The average recovery of standard material is $83 \% \sim 106 \%$ for the analysis of $\mathrm{THg}$ and $\mathrm{MeHg}$.
$\mathrm{THg}$ contents in the grit chamber influent were analyzed(Fig .3-1.). It was found that the contents of $\mathrm{THg}$ $((0.23 \pm 0.02 \sim 9.73 \pm 0.82) \times 103 \mathrm{ng} / \mathrm{L}) \quad$ were highly variable,giving average concentrations of $2.00 \times 103 \mathrm{ng} / \mathrm{L} . \mathrm{THg}$ concentrations in raw sewage varied widely,from $2 \sim 150 \mathrm{ng} / \mathrm{L}[9]$. The $\mathrm{THg}$ concentrations in the second sewage treatment plant of Jiaozuo were far above $\mathrm{THg}$ concentrations in sewage treatment plant of Winnipeg.Main reasons for this difference may be due to the different inffluent qulity and the different groundwater seepage.Inffluent $\mathrm{THg}$ concentrations has positivly correlation with TSS concentrations

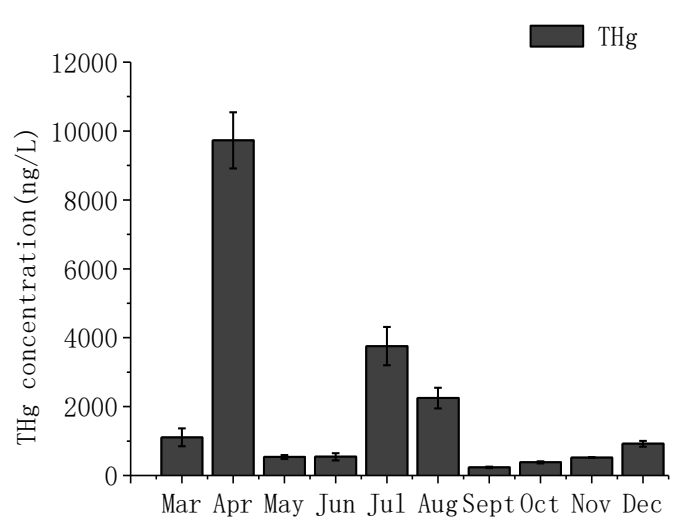

Figure 3-1 .Influent THg Concentration

\section{RESULTS AND DISCUSSION}

A. Variation of mercury in raw sewage influent

\section{1) $\mathrm{THg}$ variation in raw sewage influent}

It was found that the contents of dissolved $\mathrm{THg}$ ( $2.32 \pm 0.28 \sim 124 \pm 20.2 \mathrm{ng} / \mathrm{L})$ were highly variable(Fig .3-3), giving average concentrations of 16.2ng/L. Dissolved THg gave the highest content in August and gave lowest content in November.The ratio(Dissolved THg/THg) was relatively low $(0.04 \% \sim 5.5 \%)$ (Fig .3-4), giving average concentrations of $1.2 \% . \mathrm{THg}$ in grit chamber mainly exists with granule state.It was due to the suspended solids in the water and sediment has strong adsorption to the

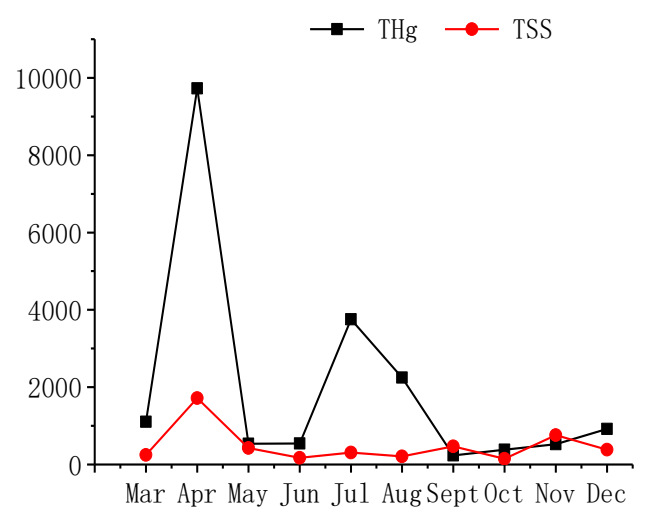

Figure 3-2 The Relationship Between Influent $\mathrm{THg}$

$(\mathrm{P}=0.003)$ ( Fig .3-2.).THg gave the highest concentration in April and gave lowest concentration in September(in grit chamber).So $\mathrm{THg}$ concentrations will be eventually rsduced with TSS removal in equipment.

mercury,leading to mercury in water migration to sediments.Concentrations of influent dissovled $\mathrm{THg}$ also spanned limited ranges $0.68-1.47 \mathrm{ng} / \mathrm{L}$ for dissolved $\mathrm{THg}$ from St.Paul Minnesota wastewater treatment plant[12].This result much less than what we determined dissolved $\mathrm{THg}$ contents,but giving average concentrations of $36 \%$ was higher than the ratio of dissolved $\mathrm{THg}$ in our sewage treatment plant.Main reasons for this difference may be due to the different influence sewage quality.

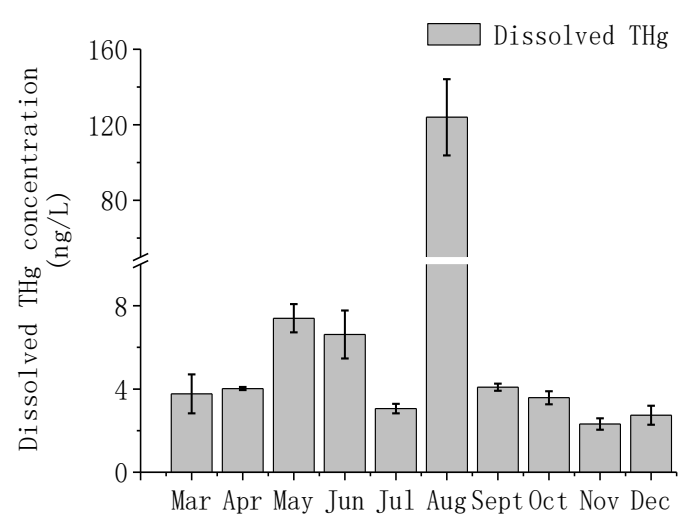

Figure3-3.Influent DissolvedTHg Concentration

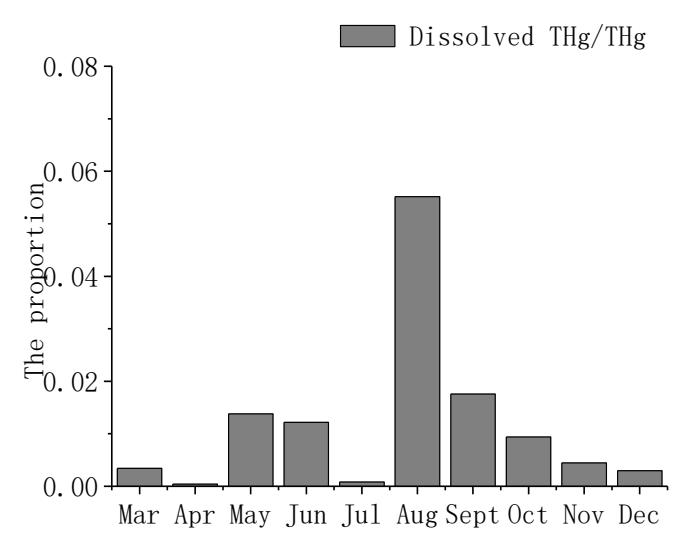

Figure3-4. The Rtio Dissolved THg Represented 
2) $\mathrm{MeHg}$ variation in raw sewage influent

It was found that the contents of $\mathrm{TMeHg}(1.46 \pm 0 \sim$ $22.6 \pm 2.86 \mathrm{ng} / \mathrm{L}$ ) were highly variable(Fig .3-5),giving average concentrations of 7.5ng/L.Inffluent $\mathrm{TMeHg}$ concentrations has correlation with TSS concentrations $(\mathrm{P}=0.032)$ (Fig .3-6). THg gave the highest content in April and gave lowest content in November in grit chamber sludge.It is simlar with the concentrations variation of $\mathrm{MeHg}$ in Onondaga County Metropolitan Wastewater Treatment Plant[13].

The contents of dissolved $\mathrm{MeHg}$ were $0.11 \pm 0.01 \sim$ $2.17 \pm 0.13 \mathrm{ng} / \mathrm{L}$, giving average concentrations of $0.59 \mathrm{ng} / \mathrm{L}$. The concentrations of dissolved $\mathrm{TMeHg}$ was higher during warmer months(may to August) than colder moths(September to December). $\mathrm{MeHg}$ is an anaerobic process and largely affected with sulfate reducing bacteria[14]. MeHg might increase with the temperature rising[15].Higher temperatures make it easier for $\mathrm{MeHg}$ in sewage pipe.It has the same phenomenon that the concentrations of influence $\mathrm{MeHg}$ increase with the temperature rising in a sewage treatment plant in New York[16].The ratio(Dissolved $\mathrm{MeHg} / \mathrm{MeHg}$ ) was 5\% $28 \%$,on average concentrations was $11.6 \%$ (Fig .3-6), it shows that $\mathrm{MeHg}$ in grit chamber mainly exists with granule state. The ratio $(\mathrm{MeHg} / \mathrm{Hg})$ was $0.23 \% \sim 1.7 \%$,on average concentrations was $11.6 \%$ ( Fig .3-7), $\mathrm{THg}$ was the main form of mercury in grit chamber influente.It was found that the ratio(Dissolved $\mathrm{MeHg} /$ Dissolved $\mathrm{THg}$ ) ) were highly variable(1.8\% 28\%), giving average ratio of $10 \%$.

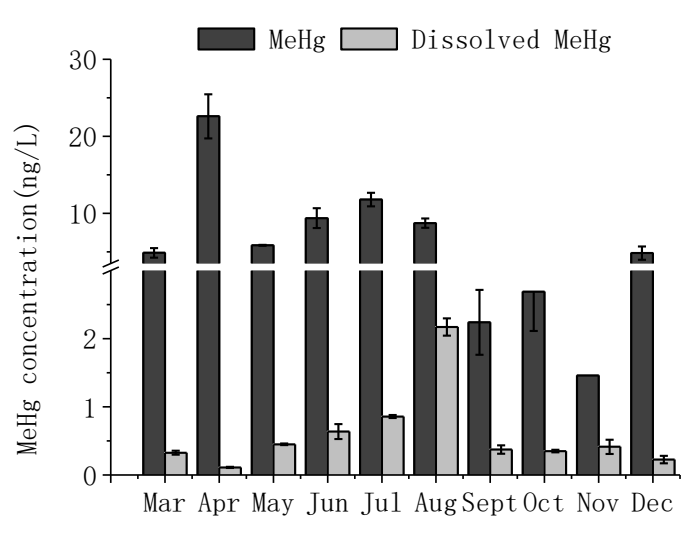

Figure 3-5.Influent $\mathrm{MeHg}$ Concentration

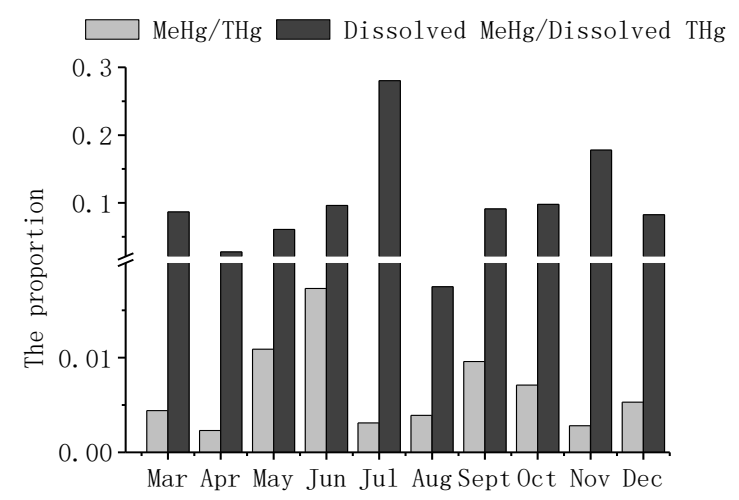

Figure3-7.The Ratio MeHg Represented of

\section{B. Variation of mercury in effluent}

\section{1) $\mathrm{THg}$ variation in effluent}

It was found that the contents of final effluent $\mathrm{THg}(1.78 \pm 0.22 \sim 43.3 \pm 0.67 \mathrm{ng} / \mathrm{L})$ were highly variable(Fig .3-8), giving average concentrations of

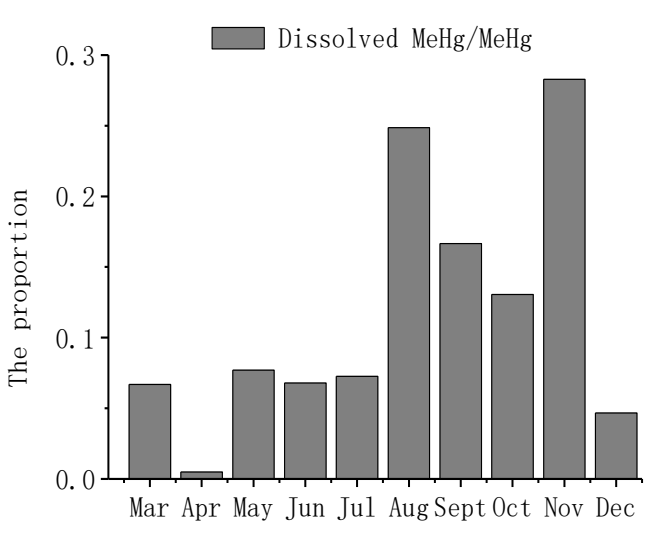

Figure3-6.The Ratio Dissolved MeHg Depresented of

10.6ng/L.THg contents of the final effluent met the requirement of "Urban sewage treatment plant pollutant discharge standard" (GB18918-2002)(1ug/L)[17].Compared with the grit chamber influent, $\mathrm{THg}$ reduced about $96.1 \%$ $99.9 \%$, the average removal rate of $98.9 \%$.It was similar with sewage treatment plant in St. Paul Minnesota(removal rate of $99 \%$ )[12],but slightly more than removal rate of wastewater treatment plant in Winnipeg[9].Probably the difference of influent sewage quality or the differences of processing treatment effect.It shows that The second sewage treatment plant of Jiaozuo have high removal efficiency for $\mathrm{THg}$.

The contents of dissolved $\mathrm{THg}$ were $0.35 \pm 0.02 \sim$ $8.03 \pm 0.09 \mathrm{ng} / \mathrm{L}$, giving average concentrations of $2.2 \mathrm{ng} / \mathrm{L}$ (final effluent). Compared with the grit chamber influent, $\mathrm{THg}$ reduced about $28.1 \% \sim 93.5 \%$, the average removal rate of $65 \%$.The fraction of dissolved $\mathrm{THg}$ accounted for $1.3 \% \sim 81 \%$ of $\mathrm{THg}$ in final effluent and higher than grit chamber influent (Fig .3-9).In the sewage treatment process,it appears the phenomenon that Mercury ions may from the form of particle state to dissolved.It is similar with wastewater treatment plant in St. Paul Minnesota [12]. 


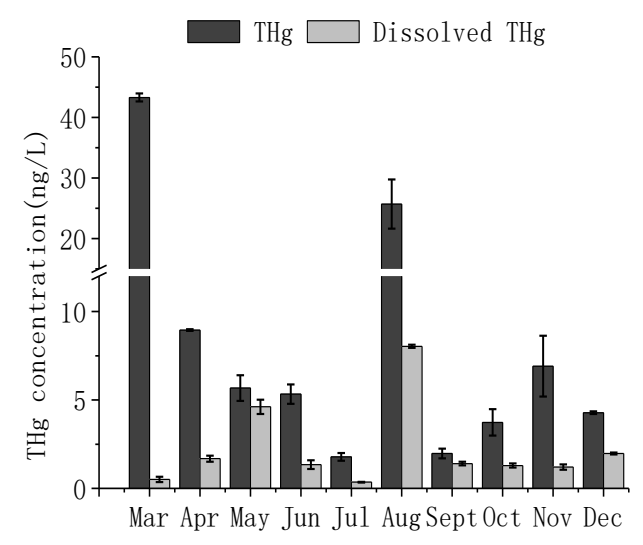

Figure 3-8.Effluent $\mathrm{THg}$ and Dissolved $\mathrm{THg}$

\section{2) $\mathrm{MeHg}$ variation in effluent}

$\mathrm{MeHg}$ content in the final effluent $(0.13 \pm 0.01 \sim$ $1.11 \pm 0.26 \mathrm{ng} / \mathrm{L})$ met the requirement of "Urban sewage treatment plant pollutant discharge standard" (GB18918-2002)(10ng/L)(Fig .3-10).81.0\% 99.4\% MeHg was removed form the raw sewage by the current sewage treatment processes. The average removal rate $(93.5 \%)$ is slightly lower than removal rate of $\mathrm{MeHg}$ in st. Paul Minnesota sewage treatment plant(97\%)[12].

The content of dissolved $\mathrm{MeHg}$ were $0.02 \pm 0.002 \sim$ $0.19 \pm 0.03 \mathrm{ng} / \mathrm{L}$, giving average concentrations of $0.1 \mathrm{ng} / \mathrm{L}$ in final effluente. $11.2 \% \sim 95.2 \%$ dissolved $\mathrm{MeHg}$ was

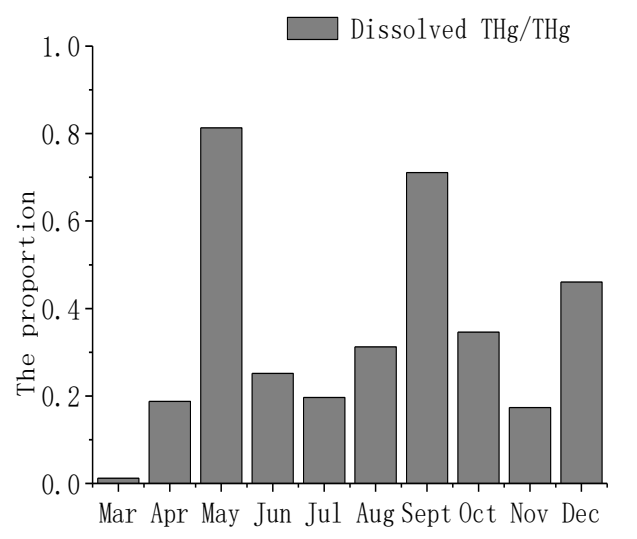

Figure 3-9. The Ratio Dissolved THg Represented

removed form the raw sewage by the current sewage treatment processes, the average removal rate of $70.7 \%$.

It was found that the ratio (dissolved $\mathrm{MeHg} / \mathrm{MeHg}$ )were highly variable (Fig .3-11),giving average ratio of 46\%.The ratio(Dissolved $\mathrm{MeHg} / \mathrm{MeHg}$ ) increased to $(10 \sim 88) \%$ in the effluente. It was due to the removal efficiency of $\mathrm{MeHg}$ higher than dissolved $\mathrm{MeHg}$ removal efficiency.MeHg represented $(0.6 \sim 20) \%$ of $\mathrm{THg}$ in final effente, on average of $7 \%$ (Fig .3-12), while it is higher than the ratio (Dissolved $\mathrm{MeHg} / \mathrm{THg}$ ) in inffluente.It shows that the removal efficiency of $\mathrm{MeHg}$ lower than $\mathrm{THg}$ removal efficiency,and final effluent mainly as form of $\mathrm{THg}$.It was found that the ratio (dissolved $\mathrm{MeHg}$ /dissolved $\mathrm{THg}$ )were highly variable (1.3\% 54\%), giving average ratio of $11 \%$ (Fig .3-12).

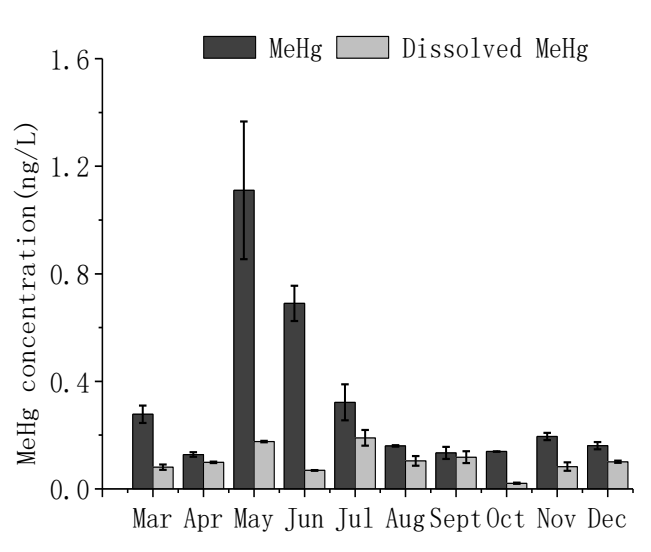

Figure3-10.Effluent $\mathrm{MeHg}$ Concentration Variation

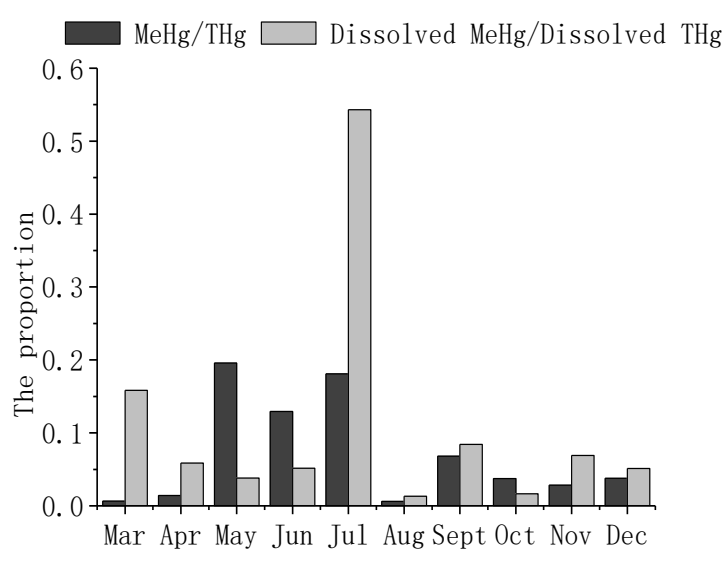

Figure3-12. The Ratio MeHg Represented

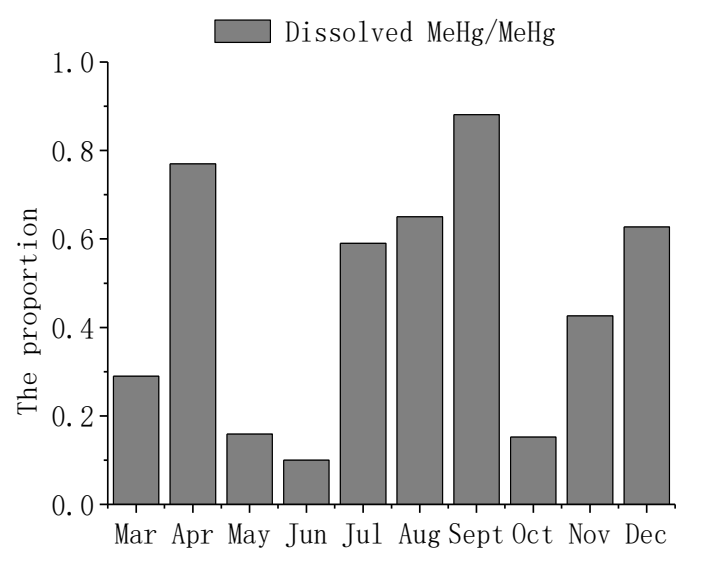

Figure3-11.The Ratio Dissolved MeHg Represented

\section{Variation of mercury in the sludge}

The content of $\mathrm{THg}$ in the press filter sludge was between $(2.02 \pm 0.29) \mathrm{mg} / \mathrm{kg}$ and $(6.88 \pm 1.42) \mathrm{mg} / \mathrm{kg}$, the average of $(3.94 \pm 0.53) \mathrm{mg} / \mathrm{kg}$ (Fig .4-1), it is higher than the national standard for soil environmental quality of gradeIII ( $\mathrm{PH}>6.5, \mathrm{Hg}$ concent $\leq 1.5 \mathrm{mg} / \mathrm{kg}[18]$.The content of $\mathrm{THg}$ in press filter sludge of the second sewage treatment plant of Jiaozuo is more greater than St.Paul Minnesota sewage wastewater treatment plant[12],probably different influent $\mathrm{THg}$ content.

The content of $\mathrm{MeHg}$ in the filter sludge was between 
$3.76 \pm 0.613 \mathrm{ng} / \mathrm{g}$ and $10.4 \pm 2.13 \mathrm{ng} / \mathrm{g}$, the average of $6.35 \pm 0.84 \mathrm{ng} / \mathrm{g}$.It reached the lowest in April and highest in March.MeHg accounted for $0.08 \% \sim 0.30 \%$ of $\mathrm{THg}$ (Fig .4-2).

\section{Potential ecological risk assessment}

Potential ecological risks of $\mathrm{Hg}$ in sludge mainly exist in the utilization of the sludge, especially in the process of land use. Geo-accumulation index method proposed and Hakanson potential ecological risk index method were used to assess the ecological risk of press filter sludge.

Geo-accumulation index method is also called Mull index, which is developed in the late $1960 \mathrm{~s}$ in Europe,It is widely used in the study of heavy metal pollution in sediment and other material degree of quantitative indicators, for its formula is as follow:

$$
\begin{gathered}
\text { Igeo }=\log 2[\mathrm{Cn} /(\mathrm{k} \times \mathrm{Bn})][19] \\
\mathrm{Bn}=0.025[20]
\end{gathered}
$$

$\mathrm{Cn}$ represents heavy metal content in the sediment.Bn represents the sediments of the element geochemical background values(This evaluation element background values selected the corresponding soil environmental background values of Henan provinc)[20].K represents the coefficient accounted for the differences of rocks around may cause changes in the background value(It is generally 1.5 ,used to characterize the sedimentary characteristics,rock geological and other effects ).Evaluation of heavy metal pollution must be considered in addition to the man-made pollution factors,environmental geochemical background values, also should be considered natural diagenesis that may cause factors of background value change. The accumulation exponential method noticed these factors, and made up for the inadequacy of other evaluation methods[21].

Hakanson put forward potential ecological risk index method,according to characteristics of heavy metal properties and environmental behavior, which is from the point of view of sedimentology proposed to evaluate heavy metals pollution in sediments.This method not only considered sediment heavy metal content,the ecological effect,environmental effect of heavy metals and toxicology, with comparable,equivalence attribute evaluation index classification method, and quantitative separated potential ecological harm degree.It is used more widely and more advanced method[22-23].The computation formula of potential ecological risk index is as follows:

Eri=TriCn/Bn[22]

$\mathrm{Cn}$ represents heavy metal content in the sediment.Bn represents the sediments of the element geochemical background values.Tri stands for a single pollutant toxicity response parameters, which reflects the relationship of heavy metal among in water phase,the sedimentary solid phase and the biological phase. Hakanson developing the standardization of the toxic response coefficient of $\mathrm{Hg}$ is 40.Geo-accumulation index and ecological risk degree were shown in TABLE I.

\begin{tabular}{|c|c|c|c|c|}
\hline $\mathrm{I}_{\mathrm{geo}}$ & Pollution Level & Pollution Degree & $\mathrm{E}_{\mathrm{r}}^{1}$ & Risk Degree \\
\hline $\mathrm{I}_{\mathrm{geo}} \leq 0$ & 0 & clean & $\mathrm{E}_{\mathrm{r}}^{1}<40$ & 低 \\
\hline $0<\mathrm{I}_{\mathrm{geo}}<1$ & 1 & Slight pollution & $40 \leq \mathrm{E}_{\mathrm{r}}^{1}<80$ & 中等 \\
\hline $2<\mathrm{I}_{\mathrm{geo}}<3$ & 3 & Moderate pollution & $80 \leq \mathrm{E}_{\mathrm{r}}^{1}<160$ & 较高 \\
\hline $4<\mathrm{I}_{\mathrm{geo}}<5$ & 5 & Heavy pollution & $160 \leq \mathrm{E}_{\mathrm{r}}^{1}<320$ & 高 \\
\hline $\mathrm{I}_{\mathrm{geo}}>5$ & 6 & Serious pollution & $\mathrm{E}_{\mathrm{r}}^{1} \geq 320$ & 极高 \\
\hline
\end{tabular}

TABLE I. GeO-ACCUMULATION INDEX AND ECOLOGICAL Risk DEgREE

In practice, Only in combination with the evaluation of regional soil, sediment and the characteristic of $\mathrm{Hg}$,evaluation purpose,appropriate evaluation method should be used.Lu fengjuan [24]used geo-accumulation index method and Hakanson potential ecological risk index method,it quantitatively determined the mercury pollution in fiver sediments and potential ecological risks, through the analysis of mercury contents in 29 river bottom sampling points in Jiading District .Shanghai.Guo fuxing[25] used Hakanson potential ecological risk index method to study distribution patterns of $\mathrm{Hg}$ in surface sediments of the Yellow Sea. The potential ecological evaluation proves that surface sediment in the major sites were in the slight ecological risk condition,but that of some sites were in moderate ecological risk condition. Level of potential ecological risk for $\mathrm{Hg}$ is medium.

Geo-accumulation index of mercury in press filter sludge is between 5.75 and 7.52 in the second sewage treatment plant of Jiaozuo,average of 6.72.The pollution level is 6 ,it belongs to the serious pollution.potential ecological risk index of mercury in press filter sludge is between 3232 and 11008 ,average of 6304 , with very high risk(TABLE II).In view of this,presss filter sludge has very high ecological risk and should not be used for farming without effective treatment. 


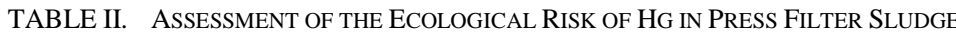

\begin{tabular}{cccccccc}
\hline & $\mathrm{T}_{\mathrm{r}}{ }^{1}$ & $\mathrm{~B}_{\mathrm{n}}(\mathrm{mg} / \mathrm{kg})$ & $\mathrm{C}_{\mathrm{n}}(\mathrm{mg} / \mathrm{kg})$ & $\mathrm{I}_{\mathrm{geo}}$ & Pollution Degree & $\mathrm{E}_{\mathrm{r}}{ }^{1}$ & Degree of Risk \\
\hline Mar & 40 & 0.025 & 6.88 & 7.52 & Serious pollution & 11008 & Very high \\
Apr & 40 & 0.025 & 4.50 & 6.91 & Serious pollution & 7200 & Very high \\
May & 40 & 0.025 & 3.56 & 6.67 & Serious pollution & 5690 & Very high \\
Jun & 40 & 0.025 & 2.50 & 6.06 & Serious pollution & 4006 & Very high \\
Jul & 40 & 0.025 & 2.02 & 5.75 & Serious pollution & 3232 & Very high \\
Aug & 40 & 0.025 & 3.17 & 6.40 & Serious pollution & 5072 & Very high \\
Sept & 40 & 0.025 & 3.97 & 6.73 & Serious pollution & 6352 & Very high \\
Oct & 40 & 0.025 & 4.22 & 6.81 & Serious pollution & 6752 & Very high \\
Nov & 40 & 0.025 & 3.09 & 6.36 & Serious pollution & 4944 & Very high \\
Dec & 40 & 0.025 & 5.53 & 7.20 & Serious pollution & 8848 & Very high \\
average & 40 & 0.025 & 3.94 & 6.72 & Serious pollution & 6304 & Very high \\
\hline
\end{tabular}

\section{CONCLUSION}

This study showed that the concentrations of $\mathrm{THg}$ and dissolved $\mathrm{THg}((0.23 \pm 0.02 \sim 9.73 \pm 0.82) \times 103 \mathrm{ng} / \mathrm{L}$ and $2.32 \pm 0.28 \sim 124 \pm 20.2 \mathrm{ng} / \mathrm{L})$ were highly variable in raw sewage with a change of time.The average of $2.00 \times 103 \mathrm{ng} / \mathrm{L}$ and 16.2ng/L.Dissolved THg only represented $(0.04 \sim 5.5) \%$ of $\mathrm{THg}$ in influent.THg in grit chamber mainly exists with granule state. The concentrations of $\mathrm{MeHg}$ and dissolved $\operatorname{MeHg}(1.46 \pm 0 \sim 22.6 \pm 2.86 \mathrm{ng} / \mathrm{L}$ and $0.11 \pm 0.01 \sim$ $2.17 \pm 0.13 \mathrm{ng} / \mathrm{L})$ were highly variable in raw sewage, average of $7.5 \mathrm{ng} / \mathrm{L}$ and $0.59 \mathrm{ng} / \mathrm{L}$.Influent $\mathrm{THg}$ and $\mathrm{MeHg}$ were correlated to $\mathrm{TSS}(\mathrm{P}=0.003, \mathrm{P}=0.032)$. Dissolved $\mathrm{MeHg}$ content was increased with the temperature rising. $\mathrm{THg}$ was the main form of mercury in grit chamber influente.

Concentrations of $\mathrm{THg}$ and dissolved $\mathrm{THg}(1.78 \pm 0.22 \sim$ $43.3 \pm 0.67 \mathrm{ng} / \mathrm{L}$ and $0.35 \pm 0.02 \sim 8.03 \pm 0.09 \mathrm{ng} / \mathrm{L})$ were highly variable in final effluent,average of $10.6 \mathrm{ng} / \mathrm{L}$ and $2.2 \mathrm{ng} / \mathrm{L} . \mathrm{THg}$ contents of the final effluent met the requirement of "Urban sewage treatment plant pollutant discharge standard" (GB18918-2002)(1ug/L).96.1\% 99.9\% $\mathrm{THg}$ and $28.1 \% \sim 93.5 \%$ dissolved $\mathrm{THg}$ were removed from the raw sewage by the current sewage treatment processes. The second sewage treatment plant of Jiaozuo have high removal efficiency for THg.Concentrations of $\mathrm{MeHg}$ and dissolved $\operatorname{MeHg}(0.13 \pm 0.01 \sim 1.11 \pm 0.26 \mathrm{ng} / \mathrm{L}$ and $0.02 \pm 0.002 \sim$ $0.19 \pm 0.03 \mathrm{ng} / \mathrm{L}$ ), average of $0.33 \mathrm{ng} / \mathrm{L}$ and $0.1 \mathrm{ng} / \mathrm{L} . \mathrm{MeHg}$ content in the final effluent met the requirement of "Urban sewage treatment plant pollutant discharge standard" (GB18918-2002)(10ng/L).81.0\% 99.4\% MeHg and $11.2 \% \sim 95.2 \%$ dissolved $\mathrm{MeHg}$ were removed from the raw sewage by the current sewage treatment processes.The ratio(Dissolved $\mathrm{MeHg} / \mathrm{MeHg}$ ) increased to $(10 \sim 88) \%$ and $\mathrm{MeHg}$ represented(0.6 20)\% of THg in final effluent, while it is higher than the ratio (Dissolved $\mathrm{MeHg} / \mathrm{THg}$ ) in inffluent.

Using the Index of geoaccumulation and potential ecological risk index method to analysis $\mathrm{THg}$ in pressure-filter sludge.The result of indicated that $\mathrm{THg}$ in pressure-filter sludge have high potential ecological risk.Thus the sludge might not be applied to farm land after suitable treatments.

\section{ACKNOWLEDGMENT}

We are grateful to the anonymous reviewers for helpful comments and critiques.

\section{REFERENCES}

[1] UNEP.Report of the global memury assessment working group on the work of its first meeting.Geneva,Switzerland,9-13 September 2002

[2] NRC(National Research Council ).2000. Toxicological Effects of Methyl mercury . Washington DC: National Academy Press

[3] The People's republic of China Statistics Bureau. China Statistical Yearbook(2014),Beijing: China Statistical prsee,2014

[4] Edward S R,Cliff I D.Introduction to Engineering \& the Environment[M].Beijing : Tsinghua Publishing House,2002

[5] Hu yaojin,Hebing.Inform of urban sludge disposal technology and the application of advanced research in China 2012.The website of China water supply and Drainage2012

[6] Linhai,Zhao lijun,Ke zhenshan. The Sduty on Contribution of Mercury from Living Community to Municipal Sewage $[\mathrm{J}]$.Environmental Science and Management.2008,33(9):71-74

[7] Ge xiaoyan,Sun xueping,Luoyang sewage plant, s sludge composition analysi-s and the feasibility of its application to soil[J].Journal of Luoyang Technology College(Natural Science Edition).2010,20(1):5-7

[8] Gilmour, C. C.; Bloom, N. S., A Case Study of Mercury and Methylmercury Dynamics in a Hg-Contaminated Municipal Wastewater Treatment Plant[J]. Water, Air, and Soil Pollution.1995,80,799-803.

[9] Bodaly, R. A.; Rudd, J. W. M.; FLETT, R. J., Effect of urban sewage treatment on total and methylmercury concentrations in effluents[J]. Biogeochemistry 1998, 40, 279-291.

[10] Lihua,Mao yuxiang,Song dangyu.Occurrence and mass balance of mercury at a sewage treatment plant.Part II :methymercury[J]. Environmental Chemistry.2014,33(8):1287-1293

[11] Balogh S J, Nollet Y H. Methlmercury input to the Mississippi River fron a large metropolitan wastewater treatment plant[J]. Science of the Total Environment, 2008, 406(15): 145-153.

[12] Solomon S;Gbondo-Tugbawa;Joseph A;McAlear. Total and methyl mercury transformations and mass loadings within a wastewater treatment plant and the impact of the effluent discharge to an alkaline hypereutrophic lake[J].Water research.2010,44 (9) 2863-2875

[13] Benoit, J.M., Gilmour, C.C., Mason, R.P.. The influence of sulfide on solidphase mercury bioavailability for methylation by pure cultures of Desulfobulbus propionicus[J]. Environ. Sci. Technol.2001, 35 (1), 127-132

[14] Ullrich SM, Tanton TW, Abdrashitova SA. Mercury in the aquatic environment: A review of factors affecting methylation.Critical Reviews in Environmental[J].Science and Technology.2001,31(3): 241-293.

[15] Gbondo-Tugbawa, S. S.; McAlear, J. A.; Driscoll, C. T.Total and methyl mercury transformations and mass loadings within a 
wastewater treatment plant and the impact of the effluent discharge to an alkaline hypereutrophic lake[J]. Water Research 2010, 44, 2863-2875.

[16] State Environmental Protection Administration of China.Urban sewage treatment plant pollutant discharge standard"(GB18918-2002) [S].Beijing: China Environment Science Press ,2002

[17] State Environmental Protection Administration of China. Standards of the people 's republic of china,Environmental quality standards for soil[S]..Beijing: State Environmental Protection Administration of China,1995

[18] ]Muller G.Index of geoaccumulation in sedinments of the Rhine Rive[J].Geojournal,1969,2(3):108-118

[19] Shao fengshou,Zhou haoyun. Key element of the soil environmental background values in Henan Province[J].1998(10):29-29

[20] Zhou xiuyan,Wang ende.Method on how to apply index of geoaccumulation to evaluate heavy metal pollution as result of inter-tidal sediments in Liaodong bay $[\mathrm{J}]$. Journal of Safety and Environmen.2004,4(2):22-24

[21] Wang L P, Zhou X W, Zheng B H.Sediments eco-environmental quality assessment in the Changjiang Estuary and its adjacent waters[J]. Acta Ecologica Sinica, 2008, 28 (5):2191-2198.

[22] Ren H L, Cui B S, Bai J H, et al. Distribution of heavy metal in paddy soil of Hani Terrace core zone and assessment on its potential ecological risk[J]. Acta EcologicaSinica, 2008, 28 (4):1625-1634

[23] Lu fengjuan. Pollution of Mercury in the sediments of river and Its potential ecological risk assessment_-Taking Jiading District, Shanghai as example[J]. Journal of Environmental Sciences.2013,39(8):2104-2147

[24] Guo fuxing,Lv songhui,Jiangtao.Distribution Patterns and Evaluation on Potential Ecological Risk of Heavy Metals in Surface Sediments of the Yellow Sea[J]. Journal of Anhui Agricultural Sciences. 2011,39 (15） : 9212—9216,9313. 